\title{
Evaluation of an enzyme-linked immunoelectrotransfer blot test for the confirmatory serodiagnosis of human toxocariasis
}

\author{
William H Roldán/ ${ }^{+}$, Yrma A Espinoza \\ Sección de Parasitología, Instituto de Medicina Tropical Daniel A. Carrión, Facultad de Medicina, \\ Universidad Nacional Mayor de San Marcos, Calle José Santos Chocano 199, CP 10138, Callao, Perú
}

To improve the serodiagnosis of human toxocariasis, a sensitive and specific enzyme-linked immunoelectrotransfer blot (EITB-IgG) test was developed and evaluated using Toxocara canis larvae excretory-secretory antigens for detecting anti-Toxocara IgG antibodies. The EITB-IgG profile of toxocariasis was characterized by comparing 27 sera from patients with toxocariasis, 110 sera from healthy subjects and 186 sera from patients with other helminth diseases (ascariasis, ancylostomiasis, trichuriasis, enterobiasis, strongyloidiasis, hymenolepiasis, diphyllobothriasis, taeniasis, cysticercosis, hydatidosis and fascioliasis). Antigenic bands of 24, 28, 30, 35, 56, 117, 136 and $152 \mathrm{kDa}$ were predominantly recognized in sera from all patients with toxocariasis. However, only bands of 24-35 kDa were highly specific for Toxocara infection (98.3\%), whereas other antigenic bands observed displayed cross-reactivity. Additionally, when the results of the EITB-IgG test were compared to those of the ELISA-IgG test, a 100\% concordance was observed for positive results in human toxocariasis cases. The concordance for negative results between the two tests for healthy subjects and patients with other helminth diseases were $96.3 \%$ and $53.7 \%$, respectively, showing that the EITB-IgG test has a higher specificity than ELISA. In conclusion, the EITB-IgG test is a very useful tool to confirm the serological diagnosis of human toxocariasis.

Key words: Toxocara - toxocariasis - immunodiagnosis - cross-reactions - EITB

Human toxocariasis is a major parasitic zoonosis, caused by infection with the larvae of Toxocara canis, the common roundworm of dogs, and less frequently, of Toxocara cati, the roundworm of cats (Schantz \& Glickman 1983, Despommier 2003). The incidence of human toxocariasis is unknown because it is a non-communicable disease in many countries. However, many cases of this disease have been reported around the world (Glickman \& Schantz 1981, Despommier 2003).

Humans become infected by ingestion of embryonated Toxocara eggs found in soil, contaminated vegetables, on dirty hands or in undercooked giblets. These eggs hatch in the proximal intestine and the released larvae penetrate the mucosa and migrate through the inner organs, causing an inflammatory response (Magnaval et al. 2001).

Toxocara cannot complete its life cycle in humans and parasite development is arrested at the larval stage. The migrating larvae give rise to the clinical syndromes of visceral larva migrans (VLM), ocular toxocariasis (OT) and a non-symptomatic infection [covert toxocariasis (CT)] (Magnaval et al. 2001). VLM includes fever, abdominal pain, malaise, weight loss, skin rash, hepatomegaly, hypergammaglobulinaemia and respiratory symptoms associated with eosinophilia (Magnaval et al. 2001). Childhood bronchial asthma has also been

+ Corresponding author: willyroldan23@hotmail.com

Received 4 May 2008

Accepted 23 January 2009 associated with toxocariasis (Oteifa et al. 1998, Chan et al. 2001). OT, caused by larvae migration to the eye, can present as strabismus, pars planitis, endophthalmitis, uveitis, retinal granuloma and retinal detachment, leading to vision loss (Gillespie et al. 1993). CT presents with a wide range of nonspecific symptoms, including cough, abdominal pain, headache and sleep and behavioral disturbances (Taylor et al. 1988).

Since the parasitological diagnosis of this infection is hampered by the impossibility of detecting larvae in tissues, the diagnosis of toxocariasis is based on clinical and serological data. The test commonly employed for the serodiagnosis of toxocariasis is ELISA using Toxocara excretory-secretory (TES) antigens to detect serum anti-Toxocara IgG antibodies (De Savigny et al. 1979, Jacquier et al. 1991). However, some components of TES antigens are not specific, demonstrating moderate cross-reactivity with other helminth species (Speiser \& Gottstein 1984, Lynch et al. 1988, Jacquier et al. 1991, Nunes et al. 1997). Sera from patients with ascariasis, filariasis, schistosomiasis and strongyloidiasis also react with TES antigens (Maizels et al. 1984, Nunes et al. 1999, Yamasaki et al. 2000). In northern countries, the TES antigens are more specific for serodiagnosis of toxocariasis, but the level of specificity is unsatisfactory in countries where co-infections with other helminths are frequent. Thus, in the tropics, Toxocara serodiagnosis remains a problem.

In order to reduce the possibility of cross-reactions with other parasites, many authors have proposed that serum absorption with extracts of a wide variety of non-homologous parasites be used (Lynch et al. 1988, Camargo et al. 1992, Nunes et al. 1997), but as the availability of these parasites is limited, their preparation is often difficult. 
Enzyme-linked immunoelectrotransfer blot (EITB) or immunoblot is a test that combines the high sensitivity of the immunoenzymatic tests with the high resolution of sodium dodecyl sulfate-polyacrylamide gel electrophoresis (SDS-PAGE); this method has been successfully adapted for the confirmatory serodiagnosis of various parasitic diseases in humans, such as schistosomiasis, hydatidosis, cysticercosis, taeniasis, fascioliasis and strongyloidiasis (Tsang et al. 1989, Hillyer et al. 1992, Verastegui et al. 1992, Valli et al. 1999, Wilkins et al. 1999, Silva et al. 2003). Western blotting for serodiagnosis of human toxocariasis has also been described (Magnaval et al. 1991).

Human helminthiasis is very frequent in various regions of Peru (Gilman et al. 1991, Marcos et al. 2005, Larocque et al. 2006, Romani et al. 2006, Yori et al. 2006, Chero et al. 2007, Cleary et al. 2007, García et al. 2007) and cross-reactions with these parasitic infections would be enough to cause confusion in the serodiagnosis of toxocariasis. Although the lack of specificity of the ELISA test for the diagnosis of human toxocariasis can be reduced by using serum pre-absorbed with regional helminth antigens (Lynch et al. 1988, Camargo et al. 1992, Nunes et al. 1997), we herein propose that it would be useful to confirm any positive results from the ELISA test (where pre-absorption is not carried out) using the EITB test on patients with suspected toxocariasis. In this study, we describe the development of an EITB test for the confirmatory serodiagnosis of human toxocariasis and compare the outputs of this assay with those of the ELISA test.

\section{PATIENTS, MATERIAL AND METHODS}

Patients and sera - Twenty seven serum samples from patients with toxocariasis diagnosed based on clinical (ocular or visceral forms of the disease), hematological and serological findings, were used to identify specific Toxocara IgG antibodies. Serum samples from 110 healthy children (with repetitive negative results for intestinal parasite examination) were used as controls. In order to assess cross-reactivity, serum samples from 186 patients with parasitological or serological confirmed helminthiasis, including ascariasis (20 cases), ancylostomiasis (10 cases), trichuriasis (15 cases), enterobiasis (12 cases), strongyloidiasis (20 cases), hymenolepiasis (19 cases), diphyllobothriasis (12 cases), taeniasis (20 cases), cysticercosis (20 cases), hydatidosis (20 cases) and fascioliasis (18 cases), were used.

Obtaining fully embryonated T. canis eggs - T. canis eggs were obtained by dissection of gravid adult female worms and incubated for 30 days at $28^{\circ} \mathrm{C}$ in a solution containing $2 \%$ formalin and $1 \%$ sodium hypochlorite for embryonation. The embryonated eggs were washed repeatedly with sterile distilled water and de-coated for 20 min in a $5 \%$ sodium hypochlorite solution at $37^{\circ} \mathrm{C}$ (Espinoza et al. 2003). The egg suspension was then washed repeatedly in sterile distilled water until all traces of chlorine had been removed.

TES antigens - Fully embryonated and de-coated $T$. canis eggs were hatched by mechanical treatment with sterile glass beads for $15 \mathrm{~min}$ and the larvae were collected in a Baermann's apparatus (Lescano 1991). The TES antigens were produced according to De Savigny (1975), modified by Bowman et al. (1987). The supernatant from Toxocara larvae cultures, in RPMI 1640 medium supplemented with HEPES and glutamine (SigmaAldrich Co, Saint Louis, USA), was removed weekly, then dialyzed against distilled water and concentrated using PEG 20,000 (mol. wt) (Sigma-Aldrich Co, Saint Louis, USA). In order to inactivate any enzymatic activity of the TES antigens, Phenylmethylsulfonyl fluoride (Sigma-Aldrich Co, Saint Louis, USA) was added to a final concentration of $0.005 \mathrm{M}$. The protein content of the TES antigens was estimated using the Lowry method (Lowry et al. 1951) and the samples were kept in aliquots at $-20^{\circ} \mathrm{C}$ until use.

Ascaris suum worm extract - This antigenic extract was obtained via a previously described method (Camargo et al. 1992). Protein concentrations of this antigenic extract samples were estimated (Lowry et al. 1951) and the samples were kept in aliquots at $20^{\circ} \mathrm{C}$ until use.

Serum absorption with A. suum worm extract - In order to assess the effect of the previous serum absorption with this heterologous antigenic extract on the results in both tests, each human serum to be assayed was pre-absorbed (v/v) with soluble $A$. suum extract at a final concentration of $60 \mu \mathrm{g} / \mathrm{ml}$ of antigen. After incubation at $37^{\circ} \mathrm{C}$ for $1 \mathrm{~h}$, dilutions of the absorbed sera were made and added to the nitrocellulose (NC) strips or microtitration wells. All the serum samples were retested twice to confirm the effect of the absorption procedure with $A$. suum antigens.

EITB-IgG - The TES antigens were electrophoretically separated and transferred to $\mathrm{NC}$ membranes (Sigma-Aldrich Co, Saint Louis, USA, NC) according to the procedures described by Tsang et al. (1991) with some modifications. The TES antigens were diluted to a final concentration of $200 \mu \mathrm{g} / \mathrm{mL}$ with sample buffer (2.5 mM Tris- $\mathrm{HCl}$, pH 8.0, containing $1 \%$ SDS, $50 \mathrm{mM}$ dithiothreitol, $0.4 \%$ glycerol and $0.025 \%$ bromophenol blue), and then heated at $65^{\circ} \mathrm{C}$ for $15 \mathrm{~min}$. The TES proteins were separated by SDS-PAGE in a $4-16 \%$ resolving gradient gel using a Miniprotean III system (Bio-Rad, Hercules, USA). Samples of TES were electrophoresed with constant current of $5 \mathrm{~mA}$ for $15 \mathrm{~min}$ and then $25 \mathrm{~mA}$, until the bromophenol blue reached the end of the gel. The relative molecular weight (MW) was calculated using the wide range Sigma-Marker ${ }^{\mathrm{TM}}$ MW standard (6.5 - $200 \mathrm{kDa}$, Sigma-Aldrich Co, Saint Louis, USA). The separated TES proteins were transferred to a $0.2 \mu \mathrm{m}$ pore size, $8 \times 8 \mathrm{~cm} \mathrm{NC}$ sheets using a Trans-blot Cell system (Bio-Rad, Hercules, USA) with a constant current of $2.0 \mathrm{~A}$ for $2 \mathrm{~h}$. The NC sheets were washed for $30 \mathrm{~min}$ with $0.01 \mathrm{M}$ phosphate-buffered saline- $0.3 \%$ Tween 20 (PBS-T), cut into 3-mm-wide strips and stored at $-20^{\circ} \mathrm{C}$ until use. NC strips were incubated with human serum samples diluted at 1:100 in PBS-T containing 5\% non-fat milk (Nestlé Carnation, USA) overnight at $4^{\circ} \mathrm{C}$. After washing three times for 5 
min with PBS-T, the strips were incubated for $3 \mathrm{~h}$ at RT with an anti-human IgG peroxidase conjugate (SigmaAldrich Co, Saint Louis, USA) diluted 1:2000 in PBST. After washing with PBS-T, the strips were developed using a freshly prepared substrate solution containing $15 \mathrm{mg}$ of 3,3' -diaminobenzidine tetrahydrochloride (Sigma-Aldrich Co, Saint Louis, USA), $30 \mathrm{~mL}$ of PBS and $10 \mu \mathrm{L}$ of $30 \%$ hydrogen peroxide. The reaction was stopped after $5 \mathrm{~min}$ by washing with tap water. Positive reactions were determined by the visualization of defined brown bands judged using the naked eye.

ELISA-IgG - Standard ELISA was performed according to the procedures described by Roldán et al. (2006) with some modifications. Briefly, 96-well flat-bottom polystyrene microtitration plates (Thermo Scientific Inc, USA) were coated with TES antigens $(0.63 \mu \mathrm{g} / \mathrm{mL})$ in $0.05 \mathrm{M}$ carbonate-bicarbonate buffer, $\mathrm{pH} 9.6(100 \mu \mathrm{L}$ per well) overnight at $4^{\circ} \mathrm{C}$. All incubation volumes were $100 \mu \mathrm{L}$ per well. The microtiter plates were washed with PBS-0.1\% Tween 20 (PBS/T) and then nonspecific reactions were blocked for $2 \mathrm{~h}$ with PBS/T containing 5\% non-fat milk (Nestlé Carnation, USA). All sera (diluted 1:200 in blocking solution) were added and incubated for $60 \mathrm{~min}$ at RT. After three washes with PBS/T, peroxidase conjugate anti-human IgG (Sigma-Aldrich Co, Saint Louis, USA) was added at a dilution of 1:4000 and the plates incubated for $60 \mathrm{~min}$ at RT. After three washes with $\mathrm{PBS} / \mathrm{T}$, the plates were developed by the addition of $0.04 \%$ o-phenylenediamine dihydrochloride (OPD, Sigma-Aldrich Co, Saint Louis, USA) and $0.03 \%$ hydrogen peroxide in $0.05 \mathrm{M}$ citrate-phosphate buffer, $\mathrm{pH}$ 5.0, and incubated in the dark for $30 \mathrm{~min}$ at RT. The reaction was stopped via the addition of $2.5 \mathrm{~N} \mathrm{H}_{2} \mathrm{SO}_{4}$. The absorbances were determined on an automatic microplate ELISA reader (Multiskan plus Labsystem version 2.01) at $492 \mathrm{~nm}$. The cut-off point for serum reactivity was calculated as the mean optical density of the negative reference sera, plus three standard deviations. Serum samples with absorbance values above the cut-off were considered positive.

Statistical analysis - The sensitivity, specificity and predictive values for both EITB-IgG and ELISA-IgG tests were calculated using $2 \times 2$ tables with a confidence interval of $95 \%$. To compare the degree of concordance between the two tests, the kappa index ( $k$ ) was used. Additionally, the Student's $t$-test $(t)$ for paired samples at a statistical significance level of $5 \%$ was used to assess the effect of serum absorption with A. suum worm extract on both the EITB-IgG and ELISA-IgG tests.

\section{RESULTS}

Using a pool of positive sera from patients with clinical and serological confirmed diagnosis of toxocariasis (four cases of OT and two cases of VLM), a total of 10 antigenic bands were obtained for different batches of TES antigens. Antigenic bands were grouped according to their MW: low MW (LMW: 24, 28, 30 and $35 \mathrm{kDa}$ ); intermediate MW (IMW: 48, 56 and $67 \mathrm{kDa}$ ) and high MW (HMW: 117, 136 and 152 kDa) (Fig. 1).

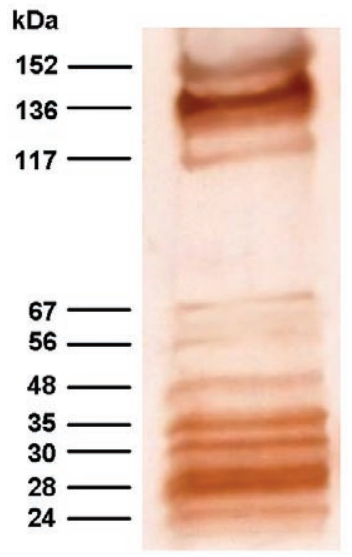

Fig. 1: immunoblot analysis of Toxocara excretory-secretory antigens against a pool sample from toxocariasis positive human sera, showing 10 antigenic bands.

All serum samples from patients with suspected diagnosis of toxocariasis were positive by the EITB-IgG test $(100 \%$ of sensitivity), showing the presence of eight major bands $(24,28,30,35,56,117,136$ and $152 \mathrm{kDa})$. The 48 and $67 \mathrm{kDa}$ bands were not efficient as the other eight bands for detecting IgG antibodies in these patients. The serum sample from one healthy control reacted with LMW bands where as sera from eight healthy controls reacted with HMW bands (Table I).

The sera from patients with other helminth diseases also were analyzed. Sera from 160 and 137 other helminth patients tested positive for HMW bands and IMW bands, respectively. Three serum samples from this group also reacted with all the bands. The frequencies of reactivity for each band with sera from different groups are summarized in Table I.

When the effect of previous serum absorption with A. suum worm extract was evaluated, LMW and HMW bands were always observed in sera from patients with toxocariasis, while the presence of almost all IMW bands was considerably reduced (Fig. 2). Furthermore, a significant reduction of positivity frequencies for HMW and IMW bands were observed in sera from patients with ascariasis $(t=3.19 ; \mathrm{p}=0.011)$, ancylostomiasis $(t=2.86 ; \mathrm{p}=0.019)$, enterobiasis $(t=2.93 ; \mathrm{p}=0.017)$, hymenolepiasis $(t=2.76 ; \mathrm{p}=0.022)$, diphyllobothriasis $(t=2.5 ; \mathrm{p}=0.034)$, taeniasis $(t=2.51 ; \mathrm{p}=0.033)$ and cysticercosis $(t=2.37 ; \mathrm{p}=0.042)$, while sera from patients with trichuriasis, strongyloidiasis, hydatidosis and fascioliasis showed no significant reduction (Table I, Fig. 2). These data suggest that HMW and IMW bands have poor specificities because of their high frequency in patients with other helminth diseases. In contrast, LMW bands $(24-35 \mathrm{kDa})$ were reactive with all sera from patients with toxocariasis, but only with four sera samples from the other groups, yielding $98.6 \%$ specificity $(95 \%$ CI, 96.6-99.5). The sensitivity and specificity for each band of the EITB-IgG test is shown in Table II. 


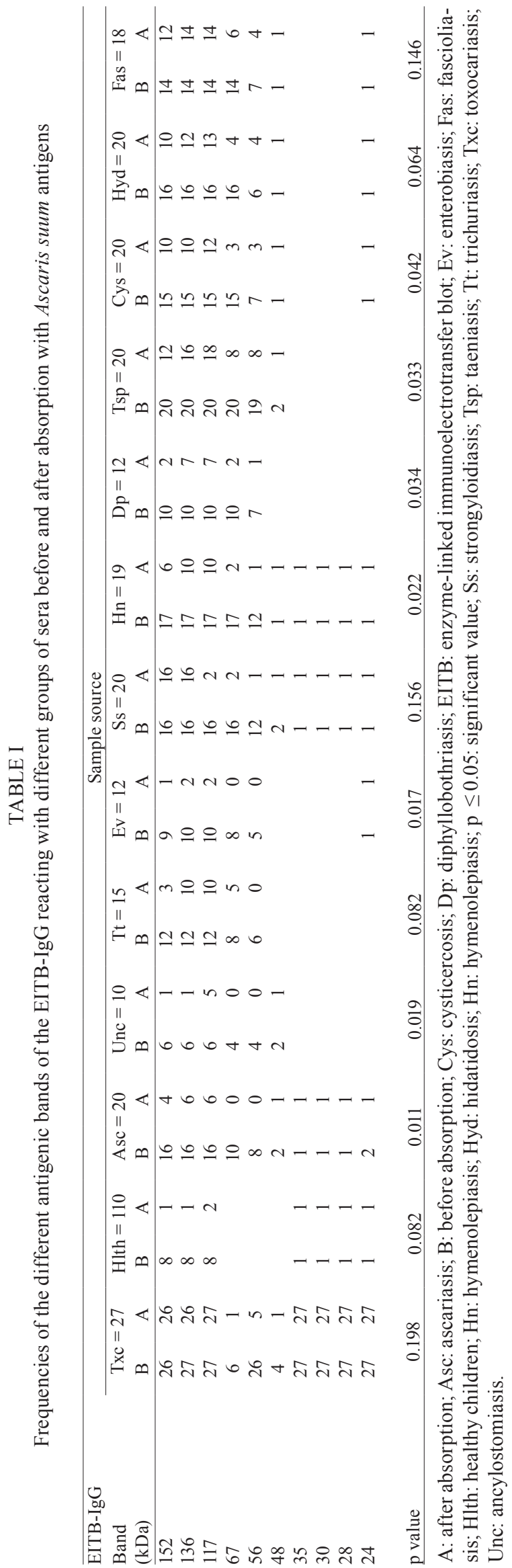

The ELISA-IgG test gave positive results for all sera from patients with suspected toxocariasis $(100 \%$ sensitivity). The same results were found when all of these sera were previously absorbed with A. suum extracts (Table III).

Additionally, positive results were also observed in $4.5 \%$ and $48.4 \%$ of sera from healthy controls and patients with other helminth diseases, respectively. The total specificity of the ELISA-IgG test was $67.9 \%(95 \%$ CI, 62.4-73). Nevertheless, when the same groups of sera were re-tested with pre-absorption with $A$. suum extracts, the frequency of positivity for sera from patients with other helminth diseases was reduced significantly to $40.32 \%(t=3.43 ; \mathrm{p}=0.005)$ (Table III).

The EITB-IgG test and ELISA-IgG test had a concordance of $100 \%(k=1.0 ; \mathrm{p}=0)$ in suspected cases of toxocariasis. The concordance of the two tests was $96.3 \%(k=0.323 ; \mathrm{p}<0.001)$ and $53.7 \%(k=0.046 ; \mathrm{p}<$ $0.01)$ in healthy controls and patients with other helminth diseases, respectively.

The reproducibility of the EITB-IgG test was very good, and there were no existing interferences with sera containing lipids, hemoglobin or billirubin.

\section{DISCUSSION}

The development of specific and sensitive tests to demonstrate the presence of antibodies in sera from patients with suspected toxocariasis is an important step towards improving diagnosis. In this study, we developed and evaluated an EITB-IgG test using TES antigens for the immunodiagnosis of human toxocariasis.

The Toxocara larvae secrete a complex set of glycoproteins containing at least 50 distinct components, as enumerated by two-dimensional SDS-PAGE analysis (Page et al. 1991, 1992a), when maintained in vitro and probably in vivo (Maizels et al. 1984, 2000, Maizels \& Page 1990, Page et al. 1992a, b). The major constituents of TES antigens are now characterized as mucins, C-type lectins and phosphatidylethanolamine-binding protein and are designated as TES-26, TES-32, TES-45, TES-55, TES-70, TES-120 and TES-400, according to their MWs on SDS-PAGE (Maizels et al. 1984, 2000, Meghji \& Maizels 1986, Gems et al. 1995, Gems \& Maizels 1996, Loukas et al. 1999, 2000).

In our study, we observed bands with a MW pattern that was different than that observed in EITB assays, but we believe that the bands of 24-28 kDa would be closely related with the TES-26, and the bands of 30 $35 \mathrm{kDa}$ would be closely related with the major TES32 band described by Maizels et al. (1984). Sugane and Oshima (1983) have also reported a protein of 35 $\mathrm{kDa}$ with a similar MW to one of our antigenic bands within the LMW group.

When we analyzed the sera from patients with suspected toxocariasis, we found that the 48 and $67-\mathrm{kDa}$ bands from the IMW group were not recognized as frequently as the other bands, being only recognized in serum samples from some patients with high titers in the ELISA-IgG test (data no shown), thus these bands have poor sensitivity for serodiagnosis of toxocariasis. These antigenic bands might be related to the TES-45, which 
is secreted in low quantities as reported by Loukas et al. (2000) and Maizels et al. (2000). In another study, Obwaller et al. (1998) reported the presence of a $65-\mathrm{kDa}$ band that binds to IgG antibodies, which might be closely related to our 67-kDa antigenic band.

The 56-kDa band from the IMW group might be related to the TES-55 reported by Maizels et al. (2000), but we believe it is more closely related to the $55 \mathrm{kDa}$ band reported by Sommerfelt et al. (2001) in a T. canis experimental infection using a pig model. Iddawella et al. (2007) also reported a specific 57-kDa antigenic band for immunodiagnostics of human toxocariasis. Nevertheless, we have found that this antigenic band had crossreactions mainly with sera from patients with ascariasis and ancylostomiasis, contradicting their affirmations.

The TES antigens show an extensive pattern of bands from 20-400 kDa when analyzed by SDS-PAGE (Maizels et al. 1984, 2000, Speiser \& Gottstein 1984). To resolve a wide spectrum of bands, it is necessary to use gradient polyacrylamide gels for separating heterogeneous polypeptide mixtures from high and low MWs, as is the case with the TES antigens.

In the present study, we found a characteristic pattern of 10 antigenic bands that were recognized by serum IgG antibodies from patients with clinical and serological confirmed cases of human toxocariasis. The MWs of these components are 24, 28, 30, 35, 48, 56, 67, 117,136 and $152 \mathrm{kDa}$. Four of these antigens bands correlate perfectly with LMW bands described by Magnaval et al. (1991).

As revealed by western blot, there are two main groups of bands present in the positive cases: one of 24-45 kDa and another group of 66-200 kDa (Magnaval et al. 1991, Nunes et al. 1997, Morales et al. 2002). These studies suggest the HMW bands can cause cross-reactivity and the LMW bands would be more specific for Toxocara. Nunes et al. (1997) identified five major components: above $205 \mathrm{kDa}$, around $205 \mathrm{kDa}, 116-97 \mathrm{kDa}, 55-50$ $\mathrm{kDa}$ and 35-29 kDa. Magnaval et al. (1991) classified the seven antigenic components into two groups, LMW (24-35 kDa) and HMW (132-200 kDa). The number of bands, as well as the exact size of the antigenic bands, varies from one publication to another; the differences can be attributed to the running conditions, the source of MW markers and other multiple inherent factors to the assay, including the presence of enzymatic activity in the TES antigens, which is often not inactivated by enzyme inhibitors added to the antigen solution. In the present study, we have used SDS-denatured and DTTreduced TES antigens, electrophoretically separated in a $4-16 \%$ gradient polyacrylamide gels in order to produce immunoblot strips for the EITB-IgG test.

All sera from patients with suspected toxocariasis were positive for the EITB-IgG test, demonstrating $100 \%$ sensitivity. However, eight sera from the control group were positive for some bands of the EITB-IgG test, mainly with antigenic bands of the HMW group. These data suggest that these patients were likely infected with other helminthes, such as Enterobius vermicularis, a worm very frequent in Peruvian children (Gilman et al. 1991) or have a mild Toxocara infection.

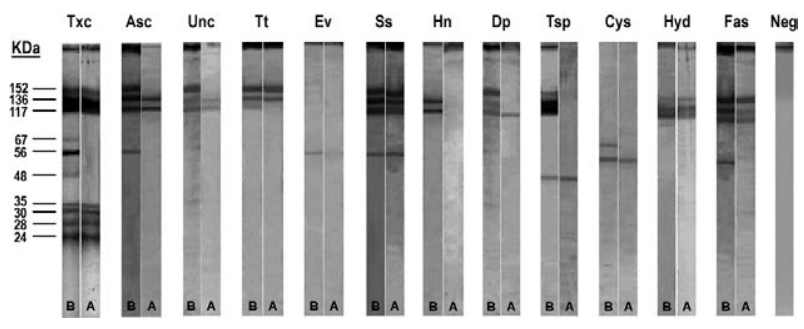

Fig. 2: representative immunoblot analysis showing the presence of specific and cross-reactive antigenic bands in sera from patients with toxocariasis and other helminth diseases before (B) and after (A) absorption with Ascaris suum antigens. A control negative serum is shown on the right.

TABLE II

Sensitivity and specificity values for different antigenic bands from the EITB-IgG test

\begin{tabular}{lcc}
\hline $\begin{array}{c}\text { EITB-IgG band } \\
(\mathrm{kDa})\end{array}$ & $\begin{array}{c}\text { Sensitivity } \\
\%\end{array}$ & $\begin{array}{c}\text { Specificity }^{a} \\
\%\end{array}$ \\
\hline 24 & $100(87.5-100.0)$ & $97(94.3-98.4)$ \\
28 & $100(87.5-100.0)$ & $98.6(96.6-100.0)$ \\
30 & $100(87.5-100.0)$ & $98.6(96.6-100.0)$ \\
35 & $100(87.5-100.0)$ & $98.6(96.6-100.0)$ \\
48 & $14.8(5.9-32.5)$ & $96.6(93.9-98.2)$ \\
56 & $96.3(81.7-99.3)$ & $74.3(69.1-79.0)$ \\
67 & $22.2(10.6-40.8)$ & $53.7(48-59.3)$ \\
117 & $100(87.5-100.0)$ & $45.9(40.4-51.6)$ \\
136 & $100(87.5-100.0)$ & $45.9(40.4-51.6)$ \\
152 & $96.3(81.7-99.3)$ & $46.3(40.7-52.0)$ \\
24 to 35 & $100(87.5-100.0)$ & $98.6(96.6-99.5)$ \\
\hline
\end{tabular}

a: confidence interval (95\%); EITB: enzyme-linked immunoelectrotransfer blot.

\section{TABLE III}

Effect of serum absorption with Ascaris suum antigens on the results of Toxocara ELISA-IgG in different groups of sera

\begin{tabular}{lcccc}
\hline ELISA-IgG & \multicolumn{2}{c}{ Before absorption } & \multicolumn{2}{c}{ After absorption } \\
Sample source (n) & Positives & $\%$ & Positives & $\%$ \\
\hline Toxocariasis (27) & 27 & 100.0 & 27 & 100.0 \\
Healthy children (110) & 5 & 4.55 & 5 & 4.55 \\
Ascariasis (20) & 10 & 50.0 & 8 & 40.0 \\
Ancylostomiasis (10) & 7 & 70.0 & 7 & 70.0 \\
Trichuriasis (15) & 9 & 60.0 & 8 & 53.3 \\
Enterobiasis (12) & 7 & 58.3 & 6 & 50.0 \\
Strongyloidiasis (20) & 10 & 50.0 & 8 & 40.0 \\
Hymenolepiasis (19) & 9 & 47.37 & 5 & 26.32 \\
Diphyllobothriasis (12) & 6 & 50.0 & 5 & 41.66 \\
Taeniasis (20) & 8 & 40.0 & 8 & 40.0 \\
Cysticercosis (20) & 9 & 45.0 & 7 & 35.0 \\
Hydatidosis (20) & 9 & 45.0 & 7 & 35.0 \\
Fascioliasis (18) & 6 & 33.3 & 6 & 33.3 \\
\hline
\end{tabular}


In sera from patients with other helminthiasis, 137 and 160 sera were positive for the IMW and HMW bands, respectively, indicating poor specificities for these bands. Because our country is an endemic area for many helminth infections (except of Schistosoma species) (Gilman et al. 1991, Marcos et al. 2005, Larocque et al. 2006, Romani et al. 2006, Yori et al. 2006, Chero et al. 2007, Cleary et al. 2007, García et al. 2007), we decided to use serum samples from people living in the high Andean Regions, as under these conditions of cold and dry weather, it is unlikely that Toxocara eggs have remained viable (Schantz 1989), thereby reducing the likelihood of co-infection. However, three serum samples from this group were also positive for LMW bands, suggesting concurrent Toxocara infections, since exclusion of a past or recent asymptomatic infection in these individuals was not possible.

We have observed a high rate of specificities for antigenic bands from the LMW group described, as the negative control sera did not react with the identified bands (Tables I, II). The ELISA-IgG and EITB-IgG tests showed a $100 \%$ of concordance for positive results and $96 \%$ of concordance for negative results in healthy controls. However, the ELISA-IgG test has shown positive results in $48.38 \%$ of patients with other helminthiasis, indicating poor specificity in regions where the other helminth infections are frequent.

The serodiagnosis of human toxocariasis is generally made by ELISA using TES antigens (De Savigny et al. 1979, Jacquier et al. 1991, Roldán et al. 2006). However, because of cross-reactions with other helminth diseases, a positive ELISA for Toxocara needs to be confirmed by western blot, which is more specific (Magnaval et al. 2001).

In an attempt to improve the specificity of the ELISAIgG test, many authors have suggested that serum pre-absorption with $A$. suum antigens can avoid cross-reactivity with other parasites, mainly with other helminths (Camargo et al. 1992, Nunes et al. 1997, Roldán et al. 2006). In a previous report, we found high rates of specificity using this procedure (Roldán et al. 2006). However, we have also observed that this antigenic extract cannot eliminate all cross-reactions, mainly in sera from patients with helminth diseases by cestodes or trematodes. In the present study, we have evaluated the effect of this antigenic extract on the results in both EITB-IgG and ELISA-IgG tests, using a wide range of serum samples.

In the group of patients with suspected toxocariasis, the IMW bands were considerably reduced (mainly the bands of 56 and $67 \mathrm{kDa}$ ), while the LMW and HMW bands remained positive in these patients.

Nunes et al. (1997) have identified one band, with MW around 55-66 kDa, as the band responsible for the cross-reactivity between $T$. canis and A. suum; this band disappears when previous absorption of serum samples with $A$. suum antigens is performed. However, Lynch et al. (1988) recognized a band with MW of $81.4 \mathrm{kDa}$ as the band responsible for a strong cross-reactivity between $T$. canis and $A$. suum extract. It is possible that reported differences in the MWs of fractions can reflect technical variations in detection and resolution of constituents or differences in methods for maintenance of larvae, such as use of enzymatic inhibitors in these preparations.

We have also observed wide variability of results when the serum absorption with $A$. suum antigens was carried out. We have observed that this antigenic extract could be an effective method to reduce the crossreactivity when helminth infections by nematodes, such as ascariasis, ancylostomiasis and enterobiasis, are also present. Nevertheless, this antigenic extract cannot reduce the cross-reactivity in nematode infections (such as trichuriasis) and strongyloidiasis. It is possible that the cross-reactive antigens from A. suum are only present in some kinds of nematodes. However, there is also the possibility that the amount of $A$. suum antigens used in the sera absorption in the present work might not be sufficient to avoid all cross-reactions in these sera.

Furthermore, we have found that the A. suum antigens may also be able to reduce cross-reactions in cases of helminth infections by cestodes, such as hymenolepiasis, diphyllobothriasis, taeniasis and cysticercosis, while cases of hydatidosis and fascioliasis are less frequently reduced.

Romasanta et al. (2003) have found the existence of cross-reactivity between Fasciola hepatica and $T$. canis, suggesting that this by taken into consideration when immunoassay tests are used in the diagnosis of parasitic infections.

With regard to cysticercosis, García et al. (2007) demonstrated the lack of cross-reactivity with anti-Taenia solium antibodies in the Toxocara-based assays, using an experimental pig model for cysticercosis.

We believe that Ascaris extracts would improve the ELISA specificity by reducing the cross-reactivity with some helminth infections, mainly with nematode parasites closely related to $\mathrm{A}$. suum. Nevertheless, it is not a good choice to reduce cross-reactions when cases of strongyloidiasis, hydatidosis or fascioliasis are implicated. Perhaps a possible solution may be the use of a more concentrated antigenic extract to avoid the crossreactive antibodies from the sera, although Elefant et al. (2006) have used lower concentrations to avoid unspecific antibodies before the ELISA assays.

Future studies are also necessary to assess other sources of heterologous antigens that can help to reduce the crossreactions in the serodiagnosis of human toxocariasis.

EITB is a more specific technique than ELISA, but much research concerning the identification of the immunodominant antigens or peptides is still needed. Studies on the purification of specific peptides may obviate the problem of cross-reactivity, and their use at appropriate concentrations can improve the ELISA, a low-cost and easy-to-use method, which appears to be useful for primary screening in endemic areas and a positive result could be confirmed by the EITB procedure.

The EITB-IgG test, using the 24-35 kDa, can easily discriminate the true cases of toxocariasis from other helminth infections, without the use of laborious procedures to elevate their specificity in an ELISA test. In conclusion, the EITB-IgG test is a useful tool to confirm the serological diagnosis of human toxocariasis, especially in cases of positive ELISA tests. 


\section{ACKNOWLEDGEMENTS}

To Dr. Hector H García, Silvia Rodriguez and Erika Perez (Cysticercosis Working Group in Peru), by the technical assistance in the development of this study, and to Prof. William R Cornejo, by some corrections of this manuscript.

\section{REFERENCES}

Bowman DD, Mika-Grieve M, Grieve RB 1987. Circulating excretory antigens levels and specific antibody responses in mice infected with Toxocara canis. Am J Trop Med Hyg 36: 75-82.

Camargo ED, Nakamura PM, Vaz AJ, da Silva MV, Chieffi PP, de Melo EO 1992. Standardization of dot-ELISA for the serological diagnosis of toxocariasis and comparison of the assay with ELISA. Rev Inst Med Trop São Paulo 34: 55-60.

Chan PWK, Anuar AK, Fong MY, Debruyne JA, Ibrahim J 2001. Toxocara seroprevalence and childhood asthma among Malaysian children. Ped Int 43: 350-353.

Chero JC, Saito M, Bustos JA, Blanco EM, Gonzalvez G, García HH, Cysticercosis Working Group in Peru 2007. Hymenolepis nana infection: symptoms and response to nitazoxanide in field conditions. Trans R Soc Trop Med Hyg 101: 203-205.

Cleary JD, Graham D, Lushbaugh WB, Nolan RL, Chapman SW 2007. Single low-dose mebendazole administered quarterly for Ascaris treatment. Am J Med Sci 333: 340-345.

De Savigny DH 1975. In vitro maintenance of Toxocara canis larvae and a simple method for the production of Toxocara E/S antigen for use in serodiagnostic tests for visceral larva migrans. $J$ Parasitol 61: 781-782.

De Savigny DH, Voller A, Woodruff AW 1979. Toxocariasis: serological diagnosis by enzyme immunoassay. J Clin Pathol 70: 284-288.

Despommier D 2003. Toxocariasis: clinical aspects, epidemiology, medical ecology and molecular aspects. Clin Microbiol Rev 16: 265-272.

Elefant GR, Shimizu SH, Sanchez MC, Jacob CM, Ferreira AW 2006. A serological follow-up of toxocariasis patients after chemotherapy based on the detection of IgG, IgA, and IgE antibodies by enzyme-linked immunosorbent assay. J Clin Lab Anal 20: 164-172.

Espinoza Y, Huapaya P, Suárez R, Chávez V, Sevilla C, Dávila E, Huiza A, Náquira C, Alva P 2003. Estandarización de la técnica de ELISA para el diagnóstico de la toxocariosis humana. An Fac Med 64: 7-12.

García HH, Cancrini G, Bartalesi F, Rodriguez S, Jimenez JA, Roldan W, Mantella A, Nicoletti A, Bartoloni A 2007. Evaluation of immunodiagnostics for toxocarosis in experimental porcine cysticercosis. Trop Med Int Health 12: 107-110.

Gems D, Ferguson CJ, Robertson BD, Nieves R, Page AP, Blaxter ML, Maizels RM 1995. An abundant, trans-spliced mRNA from Toxocara canis infective larvae encodes a $26-\mathrm{kDa}$ protein with homology to phosphatidylethanolamine-binding proteins. $J$ Biol Chem 270: 18517-18522.

Gems D, Maizels RM 1996. An abundantly expressed mucin-like protein from Toxocara canis infective larvae: the precursor of the larval surface coat glycoproteins. Proc Natl Acad Sci USA 93: $1665-16670$

Gillespie SH, Dinning NJ, Voller A, Crowcroft NS 1993. The spectrum of ocular toxocariasis. Eye 7: 415-418.

Gilman RH, Marquis GS, Miranda E 1991. Prevalence and symptoms of Enterobius vermicularis infections in a Peruvian shanty town. Trans R Soc Trop Med Hyg 85: 761-764.

Glickman LT, Schantz PM 1981. Epidemiology and pathogenesis of zoonotic toxocariasis. Epidemiol Rev 3: 230-250.
Hillyer GV, Soler de Galanes M, Rodriguez-Perez J, Bjorland J, Silva de Lagrava M, Ramirez Guzman S, Bryan RT 1992. Use of the Falcon assay ${ }^{\mathrm{TM}}$ screening test-enzyme linked immunosorbent assay (FAST-ELISA) and the enzyme-linked immunoelectrotransfer blot (EITB) to determine the prevalence of human fascioliasis in the Bolivian Altiplano. Am J Trop Med Hyg 46: 603-609.

Iddawella RD, Rajapakse RPVJ, Perera NAND, Agatsuma T 2007. Characterization of a Toxocara canis species-specific excretorysecretory antigen (TcES-57) and development of a double sandwich ELISA for diagnosis of visceral larva migrans. Korean $J$ Parasitol 45: 19-26.

Jacquier P, Gottstein B, Stinlegin Y, Eckert J 1991. Immunodiagnosis of toxocariasis in humans: evaluation of a new enzyme-linked immunosorbent assay kit. J Clin Microbiol 29: 1811-1835.

Larocque R, Casapia M, Gotuzzo E, MacLean JD, Soto JC, Rahme E, Gyorkos TW 2005. A double-blind randomized controlled trial of antenatal mebendazole to reduce low birthweight in a hookwormendemic area of Peru. Trop Med Int Health 11: 1485-1495.

Lescano SAZ 1991. Estudio epidemiológico da toxocariase na área urbana de Lima, Perú, MSc Thesis, Universidade de São Paulo, São Paulo, 50 pp.

Loukas A, Doedens A, Hintz M, Maizels RM 2000. Identification of a new C-type lectin, TES-70, secreted by infective larvae of Toxocara canis, which binds to host ligands. Parasitology 121: 545-554.

Loukas A, Mullin NP, Tetteh KK, Moens L, Maizels RM 1999. A novel C-type lectin secreted by a tissue-dwelling parasitic nematode. Curr Biol 9: 825-828.

Lowry OH, Rosenbrough NJ, Farr AL, Randall RJ 1951. Protein measurement with the folin phenol reagent. J Biol Chem 193: 265-275.

Lynch NR, Wilkes LK, Hodgen AN, Turner KJ 1988. Specificity of Toxocara ELISA in tropical populations. Parasite Immunol 10: $323-337$

Magnaval JF, Fabre R, Maurieres P, Charlet JP, De Larrard B 1991. Application of the western-blotting procedure for the immunodiagnosis of human toxocariasis. Parasitol Res 77: 697-702.

Magnaval JF, Glickman LT, Dorchies P, Morassin B 2001. Highlights of human toxocariasis. Korean J Parasitol 39: 1-11.

Maizels RM, De Savigny DH, Oglivie BM 1984. Characterization of surface excretory-secretory antigens of Toxocara canis infective larvae. Parasite Immunol 139: 207-214.

Maizels RM, Page AP 1990. Surface associated glycoproteins from Toxocara canis larval parasites. Acta Trop 47: 355-364.

Maizels RM, Tetteh KK, Loukas A 2000. Toxocara canis: genes expressed by the arrested infective larval stage of a parasitic nematode. Int J Parasitol 30: 495-508.

Marcos L, Maco V, Terashima A, Samalvides F, Espinoza JR, Gotuzzo E 2005. Fascioliasis in relatives of patients with Fasciola hepatica infection in Peru. Rev Inst Med Trop São Paulo 47: $219-222$

Meghji M, Maizels RM 1986. Biochemical properties of larval excretory-secretory glycoproteins of the parasitic nematode Toxocara canis. Mol Biochem Parasitol 18: 155-170.

Morales OL, López MC, Nicholls RS, Agudelo C 2002. Identification of Toxocara canis antigens by western blot in experimentally infected rabbits. Rev Inst Med Trop São Paulo 44: 213-216.

Nunes CM, Tundisi RN, García JF 1997. Cross reactions between Toxocara canis and Ascaris suum in the diagnosis of visceral larva migrans by western blotting technique. Rev Inst Med Trop São Paulo 39: 253-256. 
Nunes CM, Tundisi RN, Heinemann MB, Ogassawara S, Richtzenhain LJ 1999. Toxocariasis: serological diagnosis by indirect antibody competition ELISA. Rev Inst Med Trop São Paulo 41: 95-100.

Obwaller A, Jensen-Jarolim E, Auer H, Huber A, Kraft D, Aspöck H 1998. Toxocara infestation in humans: symptomatic course of toxocarosis correlates significantly with levels of IgE/anti-IgE immune complexes. Parasite Immunol 20: 311-317.

Oteifa NM, Moustafa MA, Elgozamy BM 1998. Toxocariasis as a possible cause of allergic diseases in children. J Egypt Soc Parasitol 28: 365-372.

Page AP, Hamilton AJ, Maizels RM 1992a. Toxocara canis: monoclonal antibodies to carbohydrate epitopes of secreted (TES) antigens localize to different secretion-related structures in infective larvae. Exp Parasitol 75: 56-71.

Page AP, Richards DT, Lewis JW, Omar HM, Maizels RM 1991. Comparison of isolates and species of Toxocara and Toxascaris by biosynthetic labelling of somatic and ES proteins from infective larvae. Parasitology 103: 451-464.

Page AP, Rudin W, Fluri E, Blaxter ML, Maizels RM 1992b. Toxocara canis: a labile antigenic surface coat overlying the epicuticle of infective larvae. Exp Parasitol 75: 72-86.

Roldán W, Cornejo W, Espinoza Y 2006. Evaluation of the dot-ELISA in comparison with standard ELISA for the immunodiagnosis of human toxocariasis. Mem Inst Oswaldo Cruz 101: 71-74.

Romani EL, Rodrigues-Silva R, Maldonado A Jr, Machado-Silva JR, Gomes DC 2006. Notes on human cases of cystic echinococcosis in Peru. Mem Inst Oswaldo Cruz 101: 335-337.

Romasanta A, Romero JL, Arias M, Sánchez-Andrade R, López C, Suárez JL, Díaz P, Díez-Baños P, Morrondo P, Paz-Silva A 2003. Diagnosis of parasitic zoonoses by immunoenzymatic assays - analysis of cross-reactivity among the excretory/secretory antigens of Fasciola hepatica, Toxocara canis and Ascaris suum. Immunol Invest 32: 131-142.

Schantz PM 1989. Toxocara larva migrans now. Am J Trop Med Hyg 41 (Suppl. 3): 21-34.

Schantz PM, Glickman LT 1983. Ascáridos de perros y gatos: un problema de salud pública y medicina veterinaria. Bol Oficina Sanit Panam 94: 571-586.

Silva LP, Barcelos ISC, Passos-Lima AB, Espindola FS, Campos DMB, Costa-Cruz JM 2003. Western blotting using Strongy- loides ratti antigen for the detection of IgG antibodies as confirmatory test in human strongyloidiasis. Mem Inst Oswaldo Cruz 98: 687-691.

Sommerfelt IE, Santillán G, Lopez C, Ribicich M, Franco AJ 2001. Immunological and hematological response in experimental Toxocara canis-infected pigs. Vet Parasitol 96: 127-134.

Speiser F, Gottstein B 1984. A collaborative study on larval secretoryexcretory antigens of Toxocara canis for the immunodiagnosis of human toxocariosis with ELISA. Acta Trop 41: 361-372.

Sugane K, Oshima T 1983. Purification and characterization of excretory and secretory antigen of Toxocara canis larvae. Immunology 50: $113-120$.

Taylor M, Keane C, O’Connor P, Mulvihill E, Holland C 1988. The expanded spectrum of toxocaral disease. Lancet 1: 692-695.

Tsang VCW, Boyer AE, Pau CP 1991. Enzyme-linked immunoelectrotransfer blot technique (western blot) for human immunodeficiency virus Type 1 (HIV-1) antibodies, Immunology series 15, 2nd ed., USHHS, PHS, CDC, Atlanta, Georgia, 41 pp.

Tsang VCW, Brand JA, Boyer AE 1989. An enzyme-linked immunoelectrotransfer blot assay and glycoprotein antigens for diagnosing human cysticercosis (Taenia solium). J Infect Dis 159: 50-59.

Valli LCP, Kanamura HY, Da Silva RM, Ribeiro-Rodrigues R, Dietze R 1999. Schistosomiasis mansoni: immunoblot analysis to diagnose and differentiate recent and chronic infection. Am J Trop Med Hyg 61: 302-307.

Verastegui M, Moro P, Guevara A, Rodríguez T, Miranda E, Gilman RH 1992. Enzyme-linked immunoelectrotransfer blot test for diagnosis of human hydatid disease. J Clin Microbiol 30: 1557-1561.

Wilkins PP, Allan JC, Verastegui M, Acosta M, Eason AG, Garcia HH, Gonzalez AE, Gilman RH, Tsang VCW 1999. Development of a serologic assay to detect Taenia solium taeniasis. Am J Trop Med Hyg 60: 199-204.

Yamasaki H, Araki K, Lim PKC, Zasmy N, Mak JW, Radzan T, Aoki T 2000. Development of a highly specific recombinant Toxocara canis second-stage larvae excretory-secretory antigen for immunodiagnosis of human toxocariasis. J Clin Microbiol 38: 1409-1413.

Yori PP, Kosek M, Gilman RH, Cordova J, Bern C, Chavez CB, Olortegui MP, Montalvan C, Sanchez GM, Worthen B, Worthen J, Leung F, Oré CV 2006. Seroepidemiology of strongyloidiasis in the Peruvian Amazon. Am J Trop Med Hyg 74: 97-102. 